\title{
Shoulder Function Following Latarjet Procedure for Recurrent Anterior Shoulder Instability
}

\author{
Lindiwe Fortunate Matsebula $^{1 *}$, Tatolo Sefeane ${ }^{2}$ and Abdirashid Aden ${ }^{3}$ \\ ${ }^{1}$ Orthopaedic Surgeon, Witbank Hospital, South Africa \\ ${ }^{2}$ Hand Surgery Unit Head, Baragwanath Hospital, South Africa \\ ${ }^{3}$ Head of Orthopaedic Department, Helen Joseph Hospital, South Africa
}

*Corresponding author: Dr Lindiwe Fortunate Matsebula, Orthopaedic Surgeon, Witbank Hospital, Emalahleni, 8 Hester Street, Del Judor Ext 4, Emalahleni, 1035, South Africa, Tel: +27828376946; Email: lindzmatsebula@yahoo.com

\section{Research Article}

Volume 5 Issue 1

Received Date: February 19, 2021

Published Date: April 07, 2021

DOI: $10.23880 /$ jobd-16000205

\section{Abstract}

Introduction: Anterior shoulder dislocation and recurrent glenohumeral instability is very common in the young active population. It is usually caused by trauma, and often compounded by associated bony Bankart and Hill-Sachs lesions, which distort the anatomy. This causes instability and dysfunction of the joint and these can be addressed by, amongst others, a Latarjet surgical procedure.

Hypothesis: We hypothesize that since the Latarjet procedure results in stability and good functional outcome, our results are expected to compare favourably to the rest of the published literature.

Methods: A retrospective study of 31 patients treated with the Latarjet procedure at Helen Joseph hospital, Johannesburg South Africa was undertaken during the period of January 2005 to December 2013. The minimum follow up was 6 months. Stability was assessed looking at re-dislocation rate and the clinical functional outcome was measured using the Constant Score.

Results: There were no shoulder re-dislocations and the mean Constant score was $85.35 .74 \%$ had a Constant Score above 80. $68 \%$ were pain free and $61 \%$ had normal activities of daily living while $68 \%$ had a full range of motion and $68 \%$ had full power. Conclusion: The Latarjet results in stability and good functional outcome. In our patient cohort, the Latarjet procedure provided reliable stability to the shoulder joint. Pain was alleviated, shoulder muscle power was preserved, range of shoulder motion was restored and patients did return to pre injury activities of daily living.

\section{Introduction}

The Latarjet Procedure is a surgical technique that was described by Michel Latarjet in France in 1954. He described it as an open stabilization technique of the glenohumeral joint in patients with recurrent anterior glenohumeral instability $[1,2]$. It is a procedure that entails a combination of coracoid process bone graft and a form of stability provided by the conjoined and subscapularis tendons (Figure 1). The benefits of the procedure are provision of stability, restoration of range of shoulder motion, preservation of shoulder muscle strength and return to pre morbid activities of daily living [1]. In the general population in the USA, recent studies report the rate of recurrence to range between $33-67 \%$ and in young males who are involved in athletic sporting activities; it increases to $55-82 \%$ [3]. This rate of recurrence tends to 


\section{Journal of Orthopedics \& Bone Disorders}

be higher in younger patients and decreases with age. Risk factors to recurrence are young age, athletic sports activity, males, associated bony Bankart lesion, Hill-Sachs lesion or a combination of both [3].

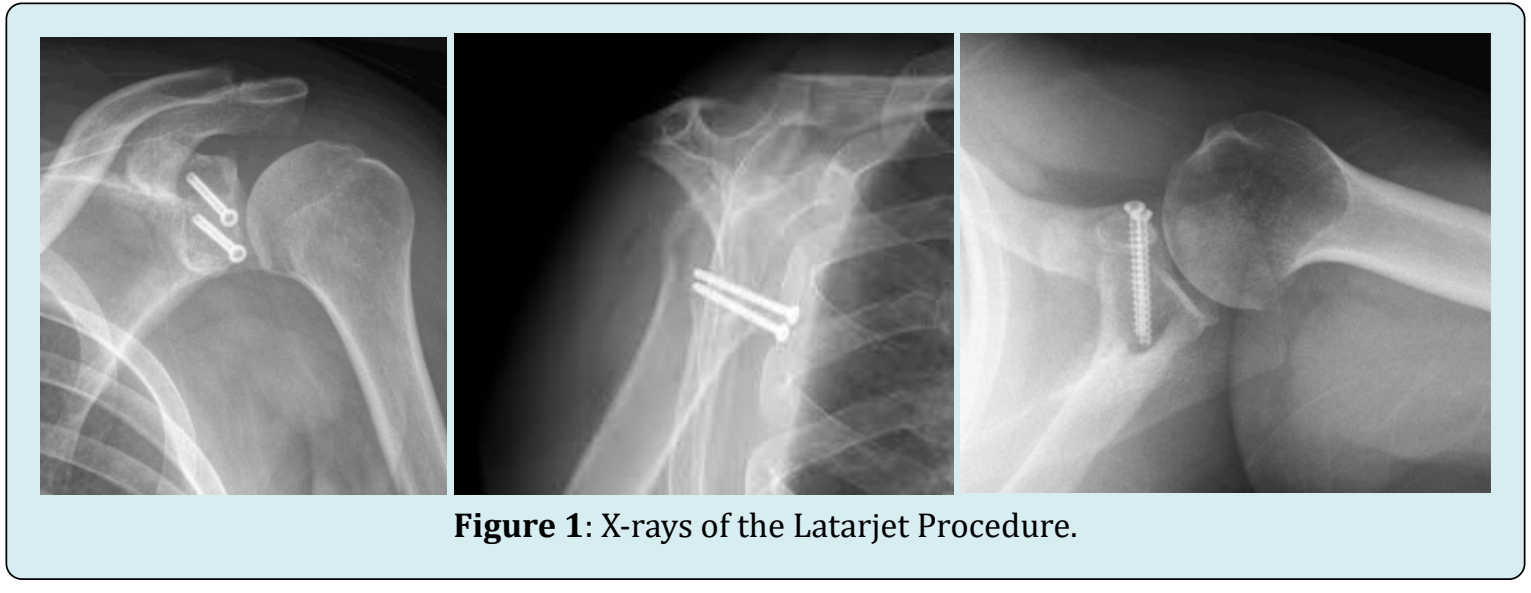

The coracoid process bone graft provides a bone block on the deficient anterior surface of the glenoid by increasing the surface area of the glenoid and subsequently increasing the arc of rotation for the head of humerus before dislocation. The conjoined tendons and subscapularis tendon provide a sling which provides stability by preventing anterior and inferior translation of the head of humerus in positions of abduction and external rotation. Historically, this coracoid process bone transfer to the glenoid was first described by Latarjet in 1954. His surgical technique entailed osteotomy and transfer of the whole coracoid process from its base together with the attached conjoined tendon. However, the procedure was modified by Helfet in 1958. He transferred only the tip of the coracoid process with the attached conjoined tendon to the glenoid. He named his modification the Bristow Procedure after his mentor W. Rowley Bristow [4]. Even though both procedures serve a common purpose of providing stability to the deficient glenoid, some researchers Giles, Joshua W et al argue that the two names Latarjet and Bristow Procedure should not be used synonymously because the biomechanics of the stabilizing mechanisms of the two are not the same. The Latarjet is superior [5].

There has been a few other modifications to the classic procedure over the years, amongst which is the congruent arc Latarjet, where the harvested coracoid process is placed at $90^{\circ}$ to its original anatomic position on the anterior surface of the scapula. This positioning was found to yield much more favourable results biomechanically by Boons, et al. [6], Noonans, et al. [7] and Burkhart, et al. [8]. The original procedure, however, still led to favourable functional outcomes [2,9-11], even though in the long term postoperative period, there has been reports of glenohumeral osteoarthritis[12-14].

The stabilizing effect of the Latarjet has been a subject of interest to many investigators over the years. Yamamoto, et al. [3] conducted a cadaveric study looking at the effect of a large glenoid bone loss on stability and found that a glenoid defect $\geq 19 \%$ was significantly big and would always be unstable regardless of soft tissue repair, and needs some form of bone grafting to enhance stability. They also looked at the sling effect of the conjoined and subscapularis tendons and reported very good stability [15]. Hovelius, et al. [16] added capsular repair as part of the surgical technique and reported good clinical results and good coracoid process graft healing.

Even though the classic Latarjet procedure was described as an open procedure [1], arthroscopic techniques have been introduced and are rapidly gaining popularity and favour among shoulder surgeons over the years. They have better post-operative cosmesis, less pain as well as quicker healing and recovery time. They also have an additional advantage in that intraoperatively concomitant intra-articular lesions can be treated using the same portals at the same setting. However, being a newer innovation they are still quite costly. They have increased operative times. The learning curve is still very steep amongst many surgeons and they require additional special training for it. Lädermann Alexandre, [17] reported that double the number of patients is required to master the arthroscopic technique, and achieve the same outcome you would otherwise achieve with the open technique. Although the arthroscopic technique is becoming very popular, it has reported complications such as intraoperative coracoid process fracture, iatrogenic nerve injuries, inaccurate coracoid process graft placement on the glenoid resulting in poor range of motion, osteolysis, non-union and recurrences of instability requiring revision [18-20]. In the long-term patients can still develop glenohumeral osteoarthritis like in the open technique [20,21]. Nevertheless, Hovelius, et al. reported that surgical stabilization of the unstable shoulder 


\section{Journal of Orthopedics \& Bone Disorders}

actually reduces the glenohumeral osteoarthritis [22].

In our institution, the open technique is still the favoured technique. Both techniques showed excellent and comparable clinical results though the arthroscopic procedure came at a much higher cost.

The main aim of our study was to establish the clinical functional outcome in our setting relative to the published literature. Our hypothesis was that since the procedure results in stability and good clinical shoulder function our results should be expected to be comparable to the published literature.

\section{Methods}

Ethical clearance was obtained to conduct the study from the Human Research Ethics Committee (Medical). This was a retrospective study. All patients between the ages of 16 and 80 that underwent a Latarjet procedure for recurrent anterior shoulder instability at our institution between January 2005 and December 2013 and were available for review were recruited to the study. Excluded were patients with anterior locked chronic shoulder dislocation, multidirectional shoulder instability, posterior shoulder dislocation and epileptic patients.

We followed a similar surgical technique as described by De Beer and Burkhart [8] for all patients (as described below). The procedures were performed by different fellowship-trained upper limb surgeons and qualified orthopaedic surgeons who work in the Upper Limb Unit at Helen Joseph Hospital.

\section{Surgical Technique}

Patients were operated under general anaesthesia. They were positioned in a semi beach chair position with the head end elevated 30 degrees. The deltopectoral approach to the shoulder was used. The cephalic vein was identified, protected and retracted laterally. The coracoid process was identified and exposed. The coracoacromial ligament and insertion of pectoralis minor were carefully dissected from the coracoid. Retractors were placed inferior and medial to the coracoid process to protect the musculocutaneous nerve, axillary neurovascular bundle and the brachial plexus. An osteotomy of the coracoid process was done at its base using a 90 degree angled blade saw. The osteotomised coracoid was harvested together with its attached conjoined tendon.

The subscapularis tendon was split at the junction of its superior and middle thirds, leaving one-third superior and two-thirds inferior. A plane was bluntly dissected between the inferior two-thirds of the subscapularis tendon and the anterior capsule. An incision was made in the capsule to expose the glenoid. The anterior glenoid neck was cleaned out and prepared for grafting using a high-speed burr. The bone surface was prepared with the burr until there was evidence of bleeding. The medial surface of the coracoid process graft was also prepared and placed on the prepared glenoid neck. It was positioned along its long axis with its inferior surface in line and in continuity with the anterior edge of the glenoid cavity. The coracoid graft was fixed onto the glenoid with two $4.0 \mathrm{~mm}$ cannulated screws.

The capsule and subscapularis tendon were repaired with ethibond sutures. Wound closure was done with vicryl and monocryl sutures. Post-operatively patients were put in a sling for six weeks. External rotation was strictly restricted at zero degrees. Physiotherapy and rehabilitation were commenced at six weeks.

The patients defined as our study population were called telephonically to come back for clinical assessment of their shoulder function in the hospital. The clinical assessment or examination was done by us, the three researchers. We noted our patients' demographics, assessed stability by looking at the rate of re-dislocation from history given by the patient, calculated the Constant Score by assessing pain, activities of daily living, range of motion and power [23]. Assessment of pain and activities of daily living was done by asking patients the questions on the Constant Score sheet and their responses to those questions were recorded accordingly. The range of shoulder motion, flexion and abduction were measured using a goniometer. Internal and external rotation was also assessed according to the Constant Score criteria. Power was assessed using a dynamometer. Finally, we looked at the correlation between the variables of the Constant Score.

Statistical analysis was then done by Statistica software version 12 (Statsoft, Tulsa, OK USA). Descriptive statistics was used on the variables and percentage calculations were worked out. The relationship between variables and distribution of data was assessed by correlation statistics. The coefficient of correlation $r, r \geq 0.1$ and $p<0.05$ were considered significant values.

\section{Results}

There were a total of 43 procedures done with 31 followed up and 11 lost to follow up. There were 21 males and 10 females with a mean age of 35 (16-74) (Figure 2). 24 shoulders were on the dominant side while 7 were on the non-dominant side. The mean follow up period was 30 months (6-96). 


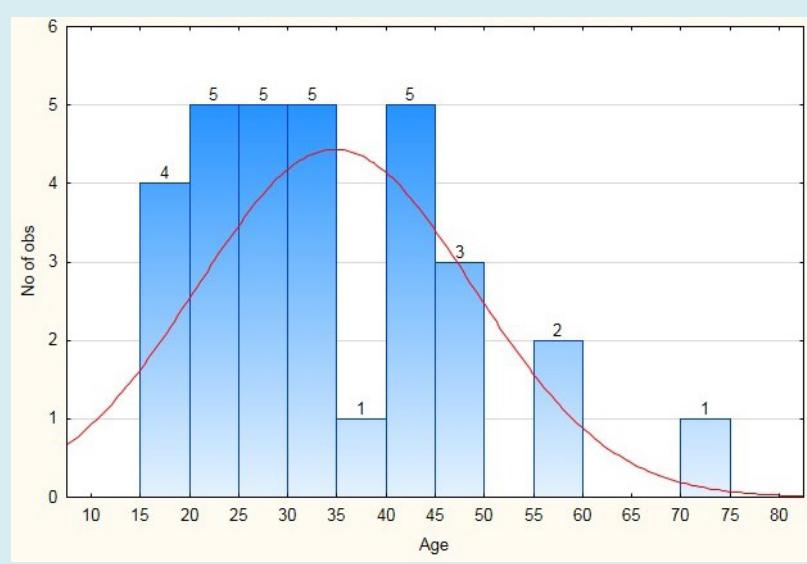

Figure 2: Ages ranged from 16-74. The mean age was 34.68, and the standard deviation was 13.95 .

No re-dislocations were reported on all patients followed up and the mean Constant score was 85.35(15$100)$ with a standard deviation of 23.43. The minimum was 15 and the maximum was 100 with $74 \%$ scoring more than
80. The standard deviation was 23.43 (Figure 3). There was a positive correlation between all components of the constant score and the constant score itself.

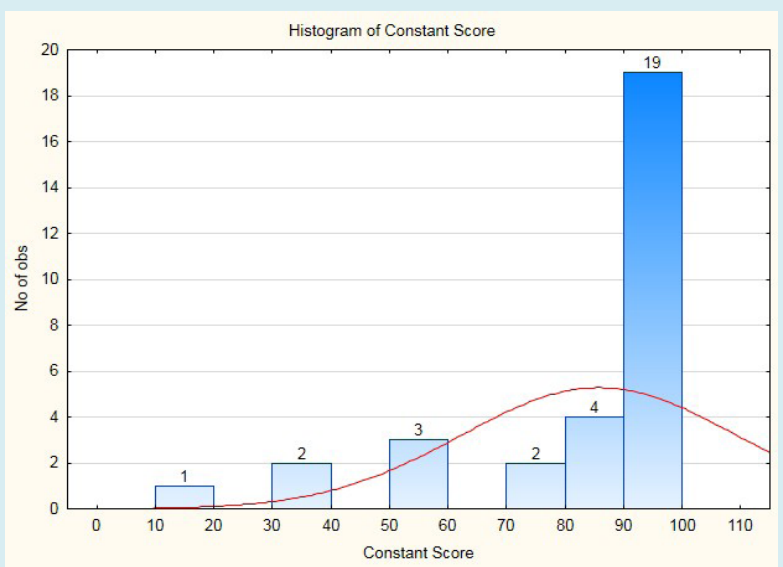

Figure 3: The mean Constant score was 85.35 . The minimum was 15 and maximum was 100 . The standard deviation was 23.43 .

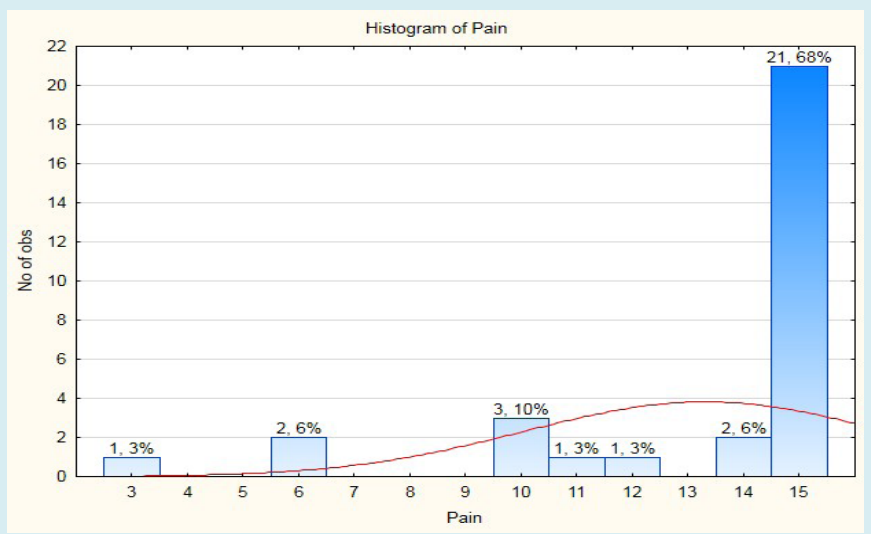

Figure 4: $68 \%$ of our patients reported no pain. The remaining 32\% still experienced some pain in their shoulders. 


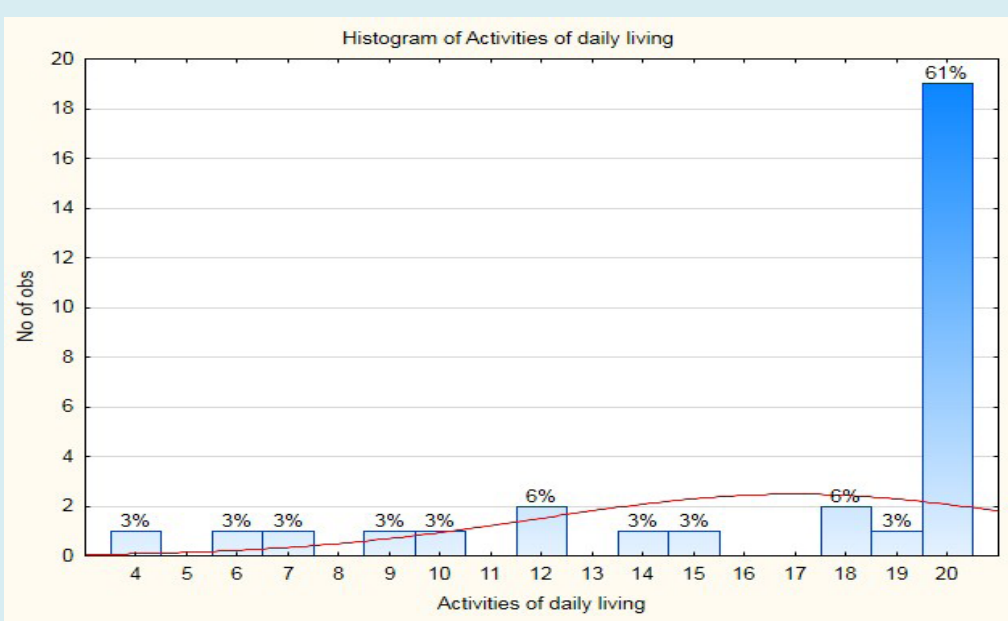

Figure 5: $61 \%$ of our patients had normal activities of daily living. They had no limitation in activities of daily living. The remaining $39 \%$ had varying degrees of limitation in activities of daily living.

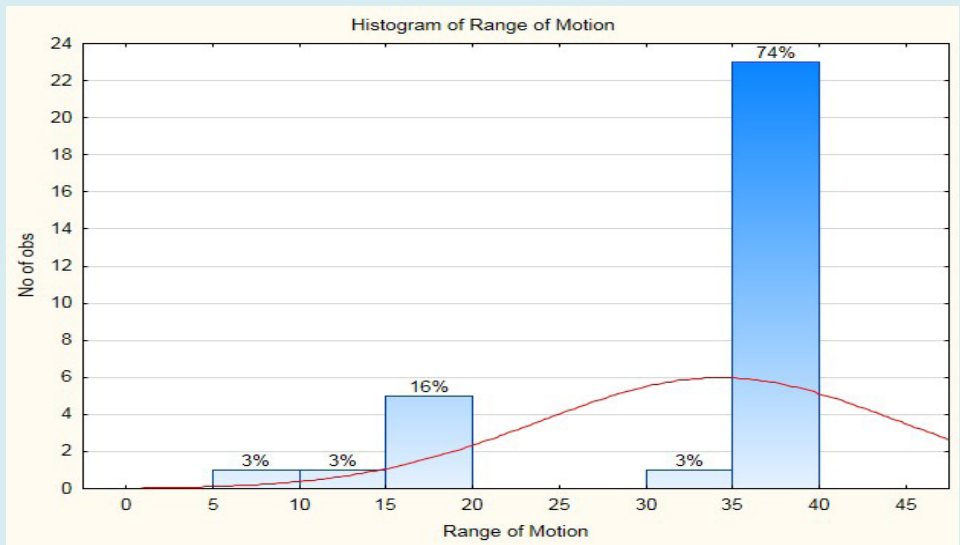

Figure 6: $65 \%$ of our patients had full range of motion. They scored 40 points for range of motion which is the maximum score for range of motion on the Constant score. $35 \%$ had limitation in range of motion.

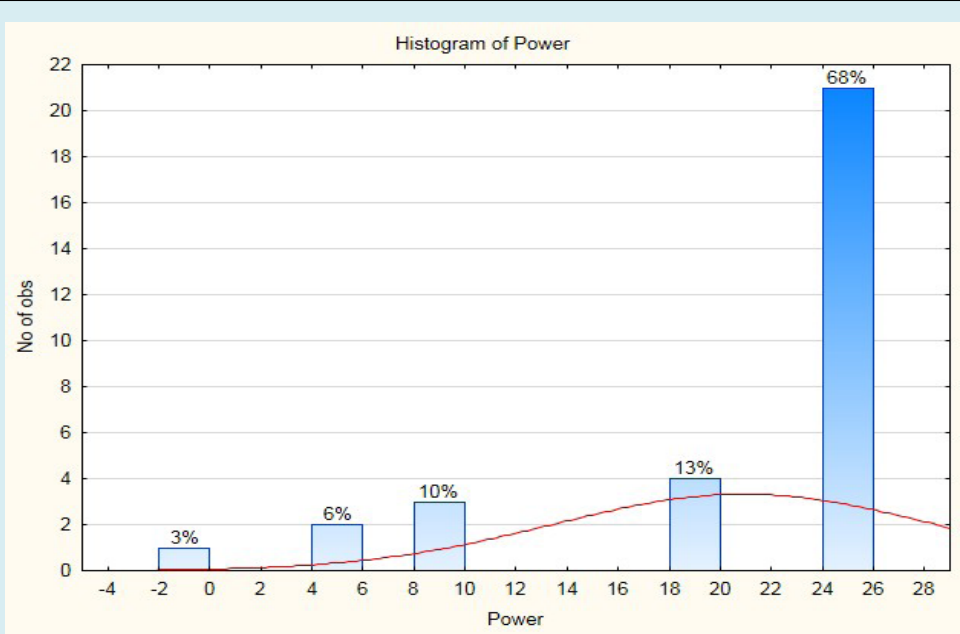

Figure 7: $68 \%$ of our patients had full power. They scored 25 points which is the maximum score for power in the Constant score. A total of $32 \%$ had loss of power. 


\section{Journal of Orthopedics \& Bone Disorders}

\section{Discussion}

The mean age 35 in our cohort is high compared to other similar studies that were done. Most studies in the literature had a mean age below 30 [6-16,19-22]. This can be attributed to Helen Joseph hospital being a referral centre. Most of the patients present late after having several dislocations and been everywhere else seeking treatment. The lower the age, the more favourable was the outcome. Increase in age is associated with an unfavourable outcome [19].

From our results, there was no re-dislocation in the cohort of 31 patients and the clinical functional outcome was good and consistent and comparable with results from other studies using the constant score (Table 1). Other studies also reported good clinical outcome, however, they used different scoring systems to evaluate the outcome.

\begin{tabular}{|c|c|c|c|c|c|}
\hline Study & $\begin{array}{c}\text { Number of patients/ } \\
\text { procedures }\end{array}$ & $\begin{array}{c}\text { Mean } \\
\text { follow up }\end{array}$ & $\begin{array}{c}\text { Re-dislocations } \\
\text { rate }\end{array}$ & $\begin{array}{c}\text { Constant } \\
\text { Score }\end{array}$ & Other scoring systems \\
\hline $\begin{array}{c}\text { Schmid, et al. [10], } \\
\text { Switzerland }\end{array}$ & 49 & 38 months & 0 & 84.6 & SSV 78.5 \\
\hline Singer, et al. [11] UK & 14 & 20.5 years & 0 & 80 & ROWE \\
\hline $\begin{array}{c}\text { Burkhart and De Beer } \\
\text { [8], USA and South } \\
\text { Africa }\end{array}$ & 102 & 7 years & $4.90 \%$ & 94.4 & Walch-Duplay 91.7 \\
\hline $\begin{array}{c}\text { Schroder, et al. [4] USA } \\
\begin{array}{c}\text { Hovelius, et al. [22] } \\
\text { Sweden }\end{array}\end{array} \quad \begin{array}{c}49 \text { patients 52 } \\
\text { procedures }\end{array}$ & 26.4 years & $9.60 \%$ & - & $\begin{array}{c}\text { ROWE 81.8 SANE 82.9 } \\
\text { WOSI 376 of 2100 }\end{array}$ \\
\hline $\begin{array}{c}\text { Hovelius, et al. [16] } \\
\text { Sweden }\end{array}$ & 118 & 15 years & $3.40 \%$ & - & ROWE \\
\hline $\begin{array}{c}\text { Garewal, et al. [2] } \\
\text { Australia }\end{array}$ & $\begin{array}{c}31 \text { patients 32 } \\
\text { procedures }\end{array}$ & $\begin{array}{c}21.3 \\
\text { months }\end{array}$ & $3 \%$ & - & $\begin{array}{c}\text { WOSI 78 MISS 75.8 } \\
\text { IInsalata 89.3 }\end{array}$ \\
\hline
\end{tabular}

Table 1: Global studies on outcome of Latarjet procedures.

We found $68 \%$ of the patients to be pain-free at the time of examination (Figure 4). They had no pain at all in all ranges of motion. There is a paucity of studies in the literature that looked at post-operative pain in isolation in the short-term. Most studies are on functional outcome looking at functional scores, which are essentially a combination of functional parameters. However, Hovelius, et al. [16] did a lot of work on the long-term results and found that most patients were pain-free. In their second study on a 15 year follow up of 118 patients, they found that $75 \%$ of the patients were pain free. Those patients who had pain, it was caused by postoperative arthritis. Other studies by Allain, et al. [12] and Singer, et al. [11] confirm that in the long term, arthropathy develops and is one of the causes of pain.

We found $61 \%$ of our patients had normal activities of daily living (Figure 5). This is consistent with other similar studies in the literature with a good functional outcome though our sample size was small compared to the larger sample size results of Hovelius, et al. [16] and Burkhart, et al. [8]. Our patients generally achieved satisfactory range of shoulder motion. $74 \%$ had full flexion and abduction, $61 \%$ achieved maximum internal rotation to between the shoulder blades and $77 \%$ had full arm elevation above the head with the shoulder in external rotation and abduction components (Figure 6). Most of the studies done in the literature looked at pure external rotation at $0^{\circ}$ and $90^{\circ}$ of abduction and it was generally found that there is a decrease of external rotation following the procedure [16]. This is attributed to the nonanatomic reconstruction of the glenoid defect following usage of the coracoid bone graft. Even though it offers the benefit of increasing the arc of rotation of the humeral head on the deficient glenoid, thus preventing dislocation, it is a non-anatomic construct which impedes the rotational movements of the joint. To prevent this limitation of external rotation, it is recommended to preserve the capsular length to its maximum when performing the procedure.

In our study, $68 \%$ of our patients had regained full muscle power at the time of examination (Figure 7). This is in keeping with the benefits of the Latarjet procedure of providing stability and range of motion while preserving the strength of the shoulder muscles. Eduardo P, et al. [24] and Paladini P, et al. [25] reported improvement and stabilization 


\section{Journal of Orthopedics \& Bone Disorders}

in isokinetic muscle power in their respective studies. They did however, report a small loss of subscapularis muscle power $(\mathrm{p}<0.01)$ following the $\mathrm{L}$ - shaped tenotomy technique and vehemently discouraged its use [25]. Even though these studies prove muscle power preservation following the procedure, they differ from our study in the sense that they specifically looked at the surgical technique used, whereas our focus was on postoperative outcome after the procedure not particularly the surgical technique. Twenty-six percent (26\%) of our patients (8 patients) had a Constant score below 80 (Figure 3). They were found to have complications; one 74 year old female had osteoarthritis of the shoulder, two patients had been treated for post-operative infection and had residual stiffness of the shoulders. One patient had pain that could not be explained by clinical examination, radiological and biochemical investigations. Two patients had non-union of the graft and one patient had a broken screw which was removed. Of note is that one of our patients scored a very poor Constant score 15 (Figure 3). This was a 43 year old male who was forty eight months post-operative at the time of the assessment for the study. On investigation of the cause of the poor function, it was found that he had a neurological (brachial plexus) fallout. He was started on a rehabilitation program and followed up closely thereafter.

Even though we obtained very good results, the limitations of the study was the small sample size 31 and only one shoulder scoring system the Constant score was used. The post-operative assessments were done as a once off event and at different post-operative intervals for the patients. This makes it difficult to make a sound comparison with the large multicentre studies done and reported in the literature. Not only being large and multicentre, different scoring systems were used to assess shoulder function, and correlations were made between the results of the different systems. However, it does stimulate prospects of conducting a larger prospective study, using more than one scoring system and with a longer follow-up period in our institution in the future.

\section{Conclusion}

In our patient cohort, the Latarjet procedure provided reliable stability to the shoulder joint. Pain was alleviated, shoulder muscle power was preserved, range of shoulder motion was restored and patients did return to pre injury activities of daily living.

\section{References}

1. Matsen FA, Steven BL, Bertlesen A, Rockwood CA, Wirth MA (2009) Chapter 1: Developmental Anatomy of the Shoulderand Anatomy of the Glenohumeral Join. In: O'Brien SJ, Voos JE, Nevasier AS, Drakos MC, (Eds.), The
Shoulder, $4^{\text {th }}$ (Edn.), Saunders Elsevier, pp: 4-29.

2. Garewal D, Evans M, Taylor D, Hoy G, Barwood S, et al. (2014) Shoulder Structure and function following the modified Latarjet procedure: A clinical and radiological review. Shoulder and Elbow 6(1): 23-28.

3. Struebel PN, Simone J, Krych AJ, Dahm D, Sperling J, et al. (2014) Anterior glenohumeral instability: A Pathologybased surgical treatment strategy. J Am Acad Orthop Surg 22(5): 283-294

4. Schroder D, Provencher M, Mologne T, Muldoon M, Cox J (2006) The modified Bristow procedure for anterior shoulder instability. 26-year outcomes in Naval Academy Midshipmen. The American journal of Sports Medicine 34(5): 778-786.

5. Giles JW, Degen RM, Johnson JA, Athwal GS (2014) The Bristow and Latarjet Procedures: Why these Techniques should not be considered synonymous. J Bone Joint Surg Am 96(16): 1340-1348.

6. Boons H, Giles J, Elkinson I, Johnson J, Athwal G (2013) Classic versus congruent coracoid positioning during the Latarjet procedure. Arthroscopy: The Journal of Arthroscopy and Related Surgery 29(2): 309-316.

7. Noonan B, Hollister S, Sekiya J, Bedi A (2014) Comparison of reconstructive procedures for glenoid bone loss associated with recurrent anterior shoulder instability. J Shoulder Elbow Surg 23(8): 1113-1119.

8. Burkhart S, De Beer J, Barth J, Criswell T, Roberts C, et al. (2007) Results of modified Latarjet reconstruction in patients with anteroinferior instability and significant bone loss. Arthroscopy. The Journal of Arthroscopic and Related Surgery 23(10): 1033-1041.

9. Joe F de Beer, Christopher Roberts (2010) Glenoid Bone Defects Latarjet with Open Congruent Arc Modification. Orthop Clin N Am 41(3): 407-415.

10. Schmid S, Farshad M, Catanzaro S, Gerber C (2012) The Latarjet procedure for the treatment of the shoulder after operative repair. A retrospective case series of forty-nine consecutive patients. J Bone Joint Surg Am 94(11): e75.

11. Singer G, Kirkland P, Emery R (1995) Coracoid transposition for recurrent anterior instability of the shoulder. A 20-year follow- up study. J Bone Joint Surg Br 77(1): 73-76.

12. Allain J, Goutallier D, Glorion C (1998) Long-term results of the Latarjet procedure for the treatment of anterior instability of the shoulder. J Bone Joint Surg Am 80(6): 841- 852. 
Journal of Orthopedics \& Bone Disorders

13. Mizuno N, Denard P, Raiss P, Melis B, Walch G (2014) Long-term results of the Latarjet procedure for anterior instability of the shoulder. J Shoulder Elbow Surg 23(11): 1691-1699.

14. Yamamoto N, Muraki T, Sperling J, Steinmann S, Cofield $\mathrm{R}$, et al. (2010) Stabilizing mechanism in bone grafting of a large glenoid defect. J Bone Joint Surg Am 92(11): 2059-2066.

15. Yamamoto N, Muraki T, An K, Sperling J, Cofield R, et al. (2013) The stabilizing mechanism of the Latarjet procedure. J Bone Joint Surg Am 95(15): 1390-1397.

16. Hovelius L, Sandström B, Olofsson A, Svensson O, Rahme H (2012) The effect of capsular repair, bone bock healing, and position on the results of the BristowLatarjet procedure (study III): long-term follow-up in 319 shoulders. J Shoulder Elbow Surg 21(5): 647-660.

17. Ladermann Alexandre (2015) Arthroscopic Latarjet Technique has advantages, but steep learning curve. Paper SS-10. Presented at: Arthroscopy Associated of North America Annual Meeting, Los Angeles.

18. Gupta A, Delaney R, Petkin K, Lafosse L (2015) Complications of the Latarjet Procedure. Current Review in Musculoskeletal Medicine 8(1): 59-66.

19. Pete D, Lunini E, Walch G (2018) Contraindications and Complications of the Latarjet Procedure. Shoulder and Elbow 10(1): 15-24.

20. Dominik M, Smolen D, Sterngerg C, Thallinger C, Hahne J, et al. (2019) 10 years of Arthroscopic Latarjet Procedure: Outcome and Complications 2019. Indian Journal of Orthopaedics 53(1): 102-110.

21. Hovelius L, Olofsson A, Sandstrom B, Augustini BG, Lars Krantz, et al. (2008) Nonoperative treatment of primary anterior shoulder dislocation in patients forty years of age and younger. A prospective twenty-five-year followup. J Bone Joint Surg 90(5): 945-952.

22. Hovelius L, Sandstrom B, Modolv Saebö (2006) One hundred eighteen Bristow-Latarjet repairs for recurrent anterior dislocation of the shoulder prospectively followed for fifteen years: Study II- the evolution of dislocation arthropathy. Journal of Shoulder and Elbow Surgery 15(3): 279-298.

23. Constant CR, Christian Gerber, Roger JH Emery, Jens Ole Søjbjerg, Frank Gohlke, et al. (2008) A review of the Constant Score: Modifications and guidelines of its use. Journal of Shoulder and Elbow Surgery 17(2): 355-361.

24. Edouard P, Beguin L, Fayolle-Minon I, Degache F, Farizon F, et al. (2010) Relationship between strength and functional indexes (Rowe and Walch-Duplay scores) after shoulder surgical stabilization by the Latarjet technique. Annals of Physical and Rehabilitation Medicine 53(8): 499-510.

25. Palladini P, Merolla G, De Santis E, Campi F, Porcellini G (2012) Long-term subscapularis strength assessment after Bristow-Latarjet procedure: Isometric study. J Shoulder Elbow Surg 21(2): 42-47. 